\title{
José Antonio Corrales. Elviña. Ciudad compacta.
}

\author{
Nicolás Martín Domínguez \\ Escuela de Arquitectura de Toledo. Universidad de Castilla la Mancha, Toledo, España. \\ E-mail: nicolasmartindominguez@gmail.com
}

\begin{abstract}
Resumen. José Antonio Corrales y Ramón Vázquez Molezún construyeron el Pabellón Español para la Exposición de Bruselas de 1957. Premiado en multitud de ocasiones, representaba la apertura de la arquitectura española hacia la Modernidad tras el letargo de su guerra civil. Considerado obra maestra, hoy día es referente para todos. Los poemas personales y dibujos de José Antonio Corrales, destilan su mirada atenta y sensible al Lugar. Sus proyectos la respuesta. Bruselas ya lo anunciaba. Ante la Ciudad Compacta, planteada por el Congreso, parece ser el mismo Corrales el que responde. En 1964, proyecta en solitario, un crecimiento para la ciudad de La Coruña, en Galicia, España. La Unidad Vecinal $n^{\circ} 3$ en el Polígono de Elviña: 400 viviendas, locales comerciales, guardería, garajes. Todo ello distribuido en bloques, torres $y$ viviendas unifamiliares. Verdadera ciudad compacta radical. La Ciudad Concentrada, es resuelta por él mediante las herramientas que mejor maneja: plantas y secciones trabajando conjuntas, afinadas, exactas y esenciales. Sin renunciar a la réplica atenta al Lugar. El sol, la orientación, los recorridos, la economía, el material, el programa, la función, el vocabulario propio del sitio... todo entra en juego. Pero también la vida de sus futuros habitantes. Propondrá una nueva vida urbana. La ciudad crece compacta pero sensible. Mediante documentos originales de su archivo, Corrales nos presentará la respuesta de un Maestro de la arquitectura. Escuchemos atentos.
\end{abstract}

Palabras clave: José Antonio Corrales, Ciudad, Compacta, Sección, Planta, Lugar, Elviña.

\section{Ciutat Vella, el centro histórico de Valencia}

En enero de 1965, José Antonio Corrales junto a Ramón Vázquez Molezún y José María Pagola de la Puente, firman el Plan General de Ordenación de La Coruña como Proyecto de Revisión del Plan de 19481.

Un Plan basado en la división de la ciudad en Polígonos y que contemplaba al sur de la ciudad el Barrio de las Flores, en el sector B del Polígono Residencial de Elviña.

El barrio estaría formado por cinco unidades vecinales encargadas por la Obra Sindical del Hogar a cinco arquitectos diferentes. Andrés F. Albalat, Ignacio Bescansa, José Antonio Corrales, Jacobo Losada y José Luque Sobrini, bajo dirección del propio Bescansa.
En cada unidad vecinal se proyectarían 400 viviendas compartiendo Centro Cívico, guarderías, escuelas y comercio.

Se construiría exnovo en la periferia de la ciudad en expansión, en la orilla derecha de la autopista de Alfonso Molina, acceso principal de la ciudad. Atendiendo a las necesidades de una ciudad en crecimiento exponencial y que, dada su morfología marcada por el límite costero, era uno de los pocos lugares de su posible extensión natural.

En el contexto de los años 60 se realizarían numerosas propuestas de auténticas "ciudades compactas", concentradas, lineales o extensivas que perseguían flexibilidad, crecimiento posterior y adaptación a la ciudad existente. Nuevos asentamientos como respuesta a los 
cambios que estaban experimentando los núcleos urbanos: como indica Leonardo Benévolo $^{2}$, motivados por el aumento de población, el mayor peso de la industria y las actividades terciarias y los cambios en los estilos de vida y la composición demográfica.

Las New Towns inglesas, que nacen como continuación de las ciudades jardín de Howard, se adaptan ahora a la mayor densidad requerida ya sin techo de número de habitantes. En estos años, ya planteadas en algunos casos como crecimiento natural de ciudades existentes y siguiendo distintas estrategias de planificación particularizadas a cada proyecto.

Los componentes del Team X proyectarán algunas de las propuestas más avanzadas y representativas de crecimientos de alta densidad. Las viviendas Golden Lane de 1952 de los Smithson, el concurso Berlín Hauptstadt de 1957 o las viviendas Robin Hood Garden de 1966-72, en las que proponían fragmentos de "ciudad densa" insertados en la urbe existente. La ciudad a distintos niveles, circulaciones diferenciadas y una nueva propuesta de relaciones sociales en las calles insertadas en los bloques, se vuelven protagonistas.

Bakema y Van den Broek, en su proyecto de bloque lineal para Tel Aviv de 1963 siguiendo la autopista, o Candilis, Josic y Woods en su proyecto para Frankfurt-Römerberg del mismo año actuando en un centro histórico destruido tras la guerra o en su proyecto de la Universidad de Berlín dos años después, participan también de estas cualidades.

Otros grupos arquitectónicos darían muestras de esta preocupación por la concentración y

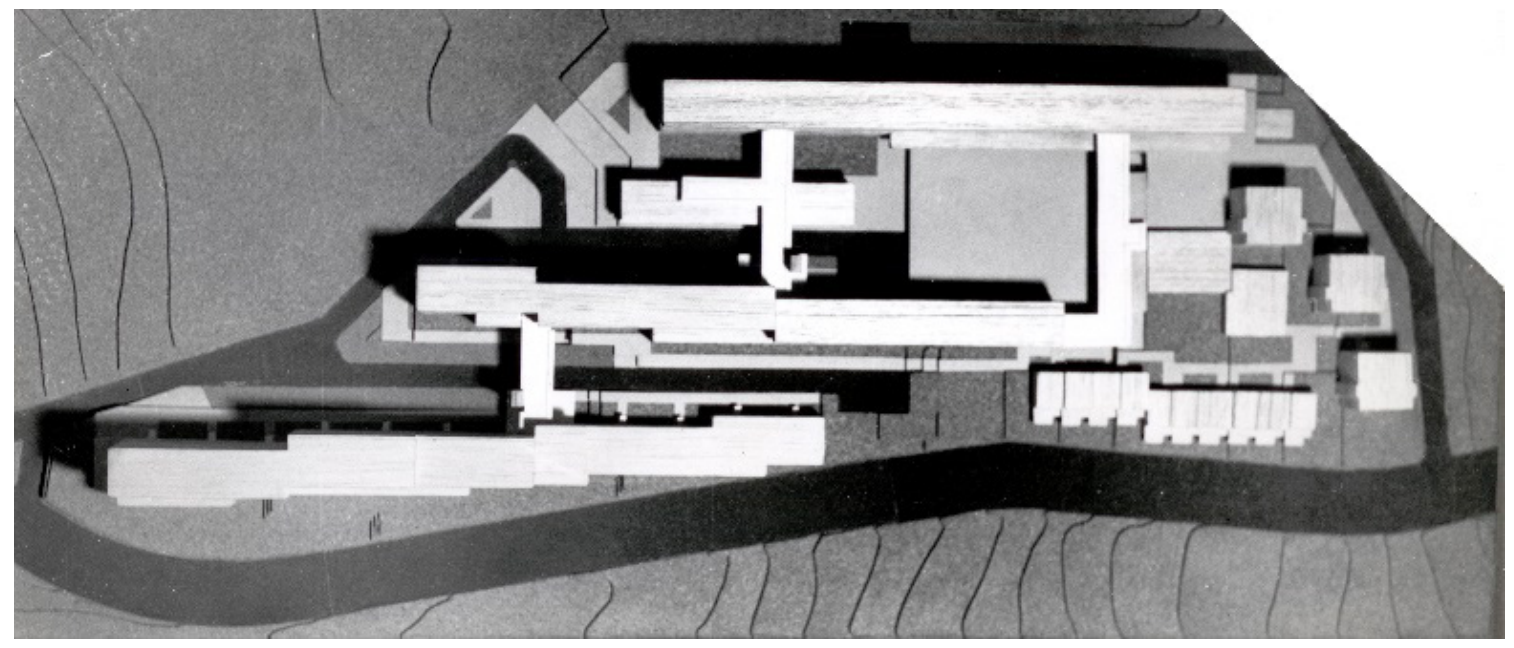

Fig. 1. Maqueta unidad vecinal n³. Archivo Corrales.

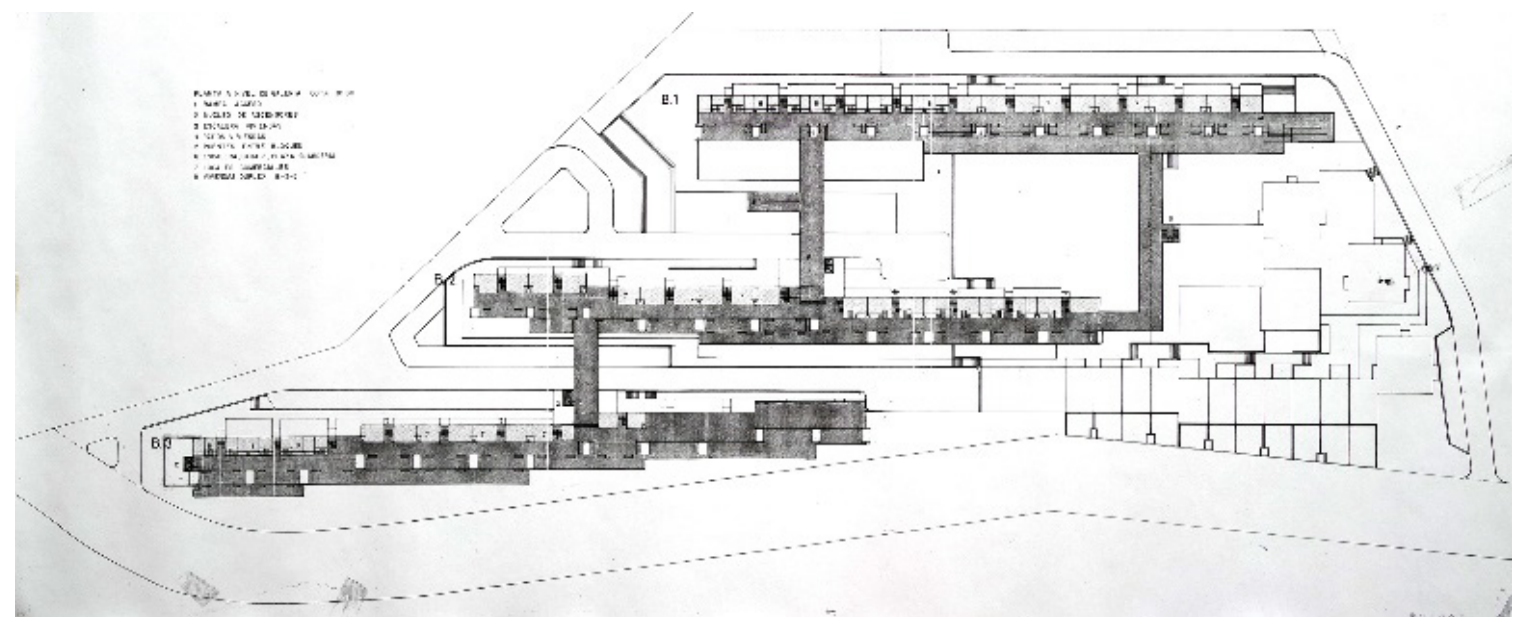

Fig. 2. Planta general por galería. Archivo Corrales. 
densidad como herramientas, cada uno desde su óptica y diversidad de intereses. Desde los Metabolistas a los Archigram, sin perder de vista otras figuras como Yona Friedman o Moshe Safdie.

En el contexto español, dos obras se acercan a las ideas defendidas por el Team $\mathrm{X}^{3}$. La Unidad Vecinal Cooperativa Pío XII en Segovia de Aracil, de Miguel y Viloria y la Unidad Vecinal de Absorción de Hortaleza de Higueras, Miró, Espinosa, Cabrera, Crespi y Weber.

Para Elviña, los terrenos donde se ubicaría el nuevo barrio presentaban una serie de inconvenientes de partida: una pronunciada pendiente dirección Este-Oeste, los molestos vientos dominantes de dirección NE y NO, junto a la existencia de un oleoducto que discurría enterrado atravesando el barrio, desde Bens hacia las instalaciones industriales situadas en el muelle de San Diego al este del puerto de La Coruña. Dentro del propio barrio, la futura Unidad Vecinal $n^{\circ} 3$ lindaría hacia el sur con la vía perimetral que rodeaba el polígono establecida por el Plan, al este con la futura unidad vecinal 2 y al oeste con la 4 . Hacia el norte, con un espacio libre destinado a equipamientos comunes a todas las Unidades que formaban el barrio ${ }^{4}$.

El programa requerido establecía una alta densidad de 520 habitantes por hectárea, junto a guarderías infantiles, aparcamientos, garajes cubierto y comercio primario ${ }^{5}$, que también debían ser resueltos.

Corrales: "Planteamos el organigrama y la ordenación general siguiendo unas pautas inspiradas en los presupuestos del Movimiento Moderno-todavía en boga en aquel momento-, en la Carta de Atenas y en todas aquellas teorías de entonces... Esta idea tenía que ver con el soleamiento, diferente según la fachada esté orientada a mediodía o al norte." 6

"...adoptamos la solución técnica de sustituir las calles por espacios libres entre bloques y con un destino concreto - huyendo asi de posibles tierras de nadie, llamadas a menudo "zonas verdes" con demasiado optimismo-: espacios públicos comunes, pavimentados, bien organizados y diferenciados." 7

A José Antonio Corrales le correspondió desarrollar la unidad vecinal $n^{0} 3$. Situada en el extremo meridional del barrio, el conjunto

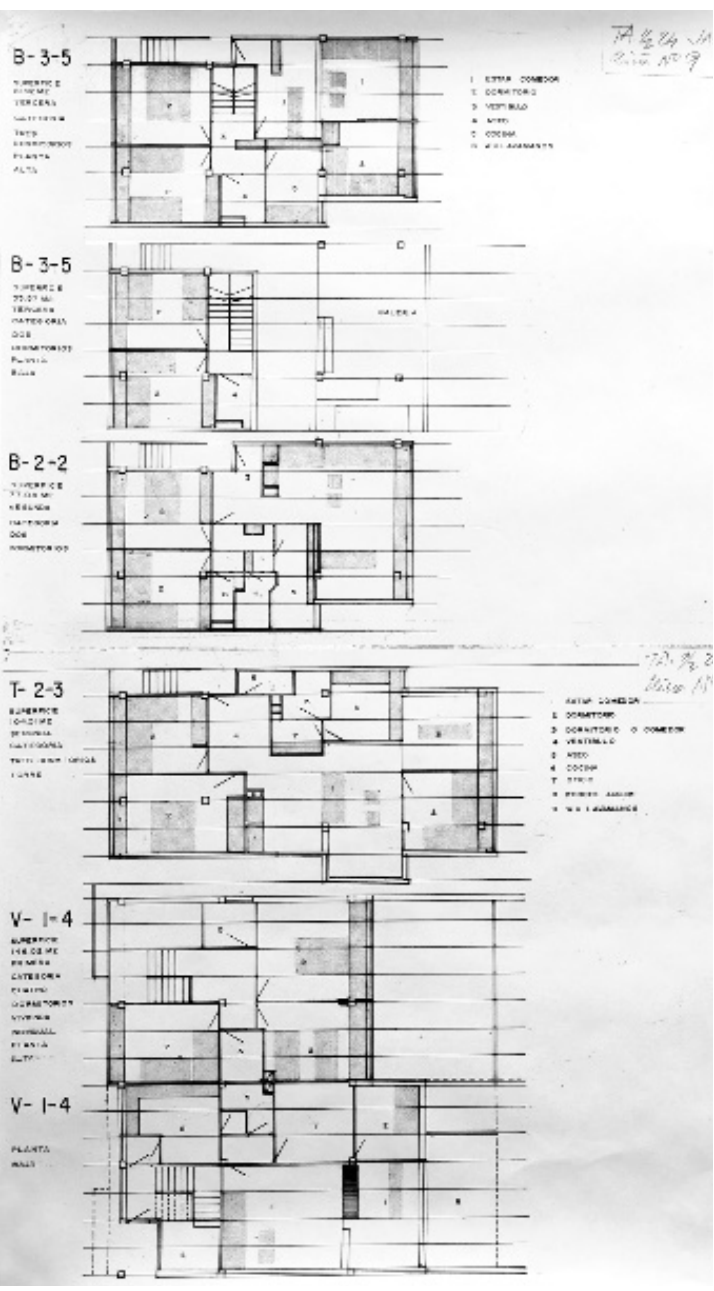

Fig. 3. Extracto tipos de vivienda. Archivo Corrales.

estaba formado por tres bloques lineales que, con orientación norte-sur directa, discurrían paralelos entre ellos y perpendiculares a las líneas de nivel. Distanciados para no quitarse el sol, discurrían hasta el límite marcado por el oleoducto enterrado, protegiéndose entre ellos de los vientos dominantes. Una galería peatonal, abierta por su fachada sur, discurría a media altura por cada uno de ellos. Las galerías se comunicaban entre sí mediante un sistema de puentes, que permitían un recorrido continuo y en altura entre bloques. Se completaba la actuación con tres torres de cinco plantas situadas al este de la parcela junto a diez viviendas individuales adosadas con jardín propio. Remataba la unidad vecinal una guardería, dos edificios comerciales bajo las pasarelas y una plaza comunitaria que cubría un reducido aparcamiento.

Corrales proponía un auténtico ejercicio 

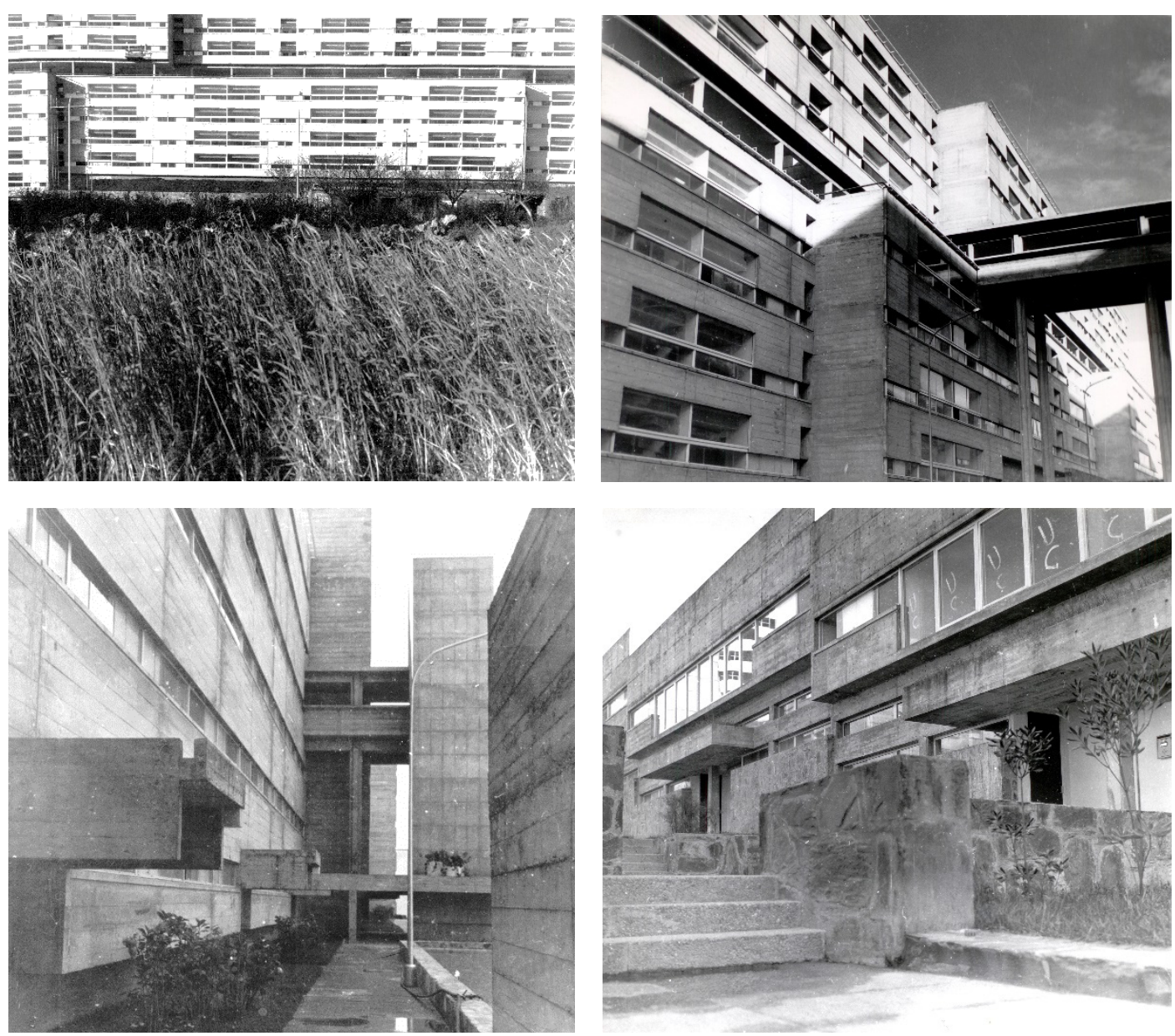

Fig 4: Izquierda, arriba. Fachada sur, bloque 3. Archivo Corrales.

Fig 5: Derecha, arriba. Galería de conexión. Archivo Corrales.

Fig 6: Izquierda, abajo. Portales-fachadas norte. Archivo Corrales.

Fig 7: Derecha, abajo. Viviendas unifamiliares. Archivo Corrales.

de Ciudad Compacta al entender desde sus orígenes todo el proyecto de manera concentrada y unitaria, aunque sensible en cada punto a las distintas necesidades requeridas. Desde las piezas residenciales propuestas en sus variantes tipológicas, sin rehuir ninguna de ellas, o las piezas comerciales y la guardería, hasta los espacios abiertos existentes nunca considerados residuales. Entre lo construido y lo vaciado Corrales proponía una verdadera escultura, persiguiendo borrar los límites para favorecer la vida urbana y los nexos sociales.

Corrales: “...los bloques se disponen en tensión recíproca, ligados y modelados como un solo edificio. Se busca que las partes y el todo se confundan y que éste sea consecuencia de la integración de aquellas. Edificación y urbanización borran sus límites: la parte viva que existe en esta frontera, como en tantas, no se anula; se intenta desarrollarla.

Se intenta, dentro de la libertad e independencia, establecer formas que favorezcan nexos sociales. Es grave el problema de conjuntos actuales sin vida urbana."

"Entonces, y aunque el bloque tuviese una determinada profundidad, el piso de arriba podía ser menos profundo o al revés... Todo formaba una macla tratada como una escultura. Habia que ver los tres bloques en conjunto y la interacción formal de uno con respecto al otro. Si un bloque estaba como metido en un determinado sentido, el complementario compensaba tal disposición."

Corrales proponía dos vías rodadas principales desde la carretera perimetral. Una al este que discurriendo paralela al bloque 
1 por su fachada norte daba servicio a los aparcamientos en superficie del bloque y de las torres. La segunda penetración, arrancaba en la cota más baja del barrio, en su extremo oeste y discurría paralela al trazado del oleoducto enterrado. Después se bifurcaba en dos vías que discurrían paralelas a las fachadas norte de los bloques 2 y 3 . Cada una de ellas al final de su recorrido desembocaba en los aparcamientos de cada bloque. La paralela al bloque 2 terminaba en un garaje cubierto de 65 plazas sobre el que se situaba la plaza central con salida directa a la calle. También contemplaba una isleta con vuelta para una futura parada de autobuses.

Las circulaciones peatonales discurrían a nivel de calle por la fachada norte de cada uno de los bloques donde se ubicaban los portales y una red complementaria para acceder a las torres y a las viviendas individuales. Por el interior de cada bloque, la galería y los puentes completaban las circulaciones.

Corrales: "Las dos redes inferior y superior se cumplimentan y producen una serie de caminos lógicos y al mismo tiempo variados, es decir que cada vecino puede llegar siempre a su casa por distintos caminos, lo cual siempre producirá una sensación de independencia." 10

La alta densidad que se preveía para el barrio obligó a los arquitectos de las distintas unidades vecinales a aumentar la altura de las edificaciones proyectadas y por tanto a la aparición del ascensor. En la propuesta de Corrales, al perseguir la doble orientación de las viviendas -cruzando éstas por completo la crujía del bloque de lado a lado- le obligaba a introducir ascensores cada dos viviendas. Un número tan elevado de ascensores hacía inviable $\mathrm{su}$ proyecto, proponiendo como solución la galería de comunicación horizontal. Siempre a la misma cota arrancaba en su recorrido a nivel de calle en el bloque 1. Debido a la caída del terreno este-oeste llegaba a alcanzar las cinco alturas en el extremo opuesto de la parcela.

Corrales conseguiría reducir así a tres núcleos de ascensores -dos ascensores por núcleo- los necesarios para toda la actuación. Para las torres, se permitían sus cinco alturas sin elevador y para las viviendas individuales no eran necesarios. Los ubicaría en el testero oeste del bloque 3 , y en las pasarelas que cruzaban entre bloques.

Corrales: "Es decir, que se podía subir en ascensor hasta la galería y, a partir de ahi, las tres plantas restantes se hacían a pie; además, la galería al sol podía servir para pasear y habia unas tiendas de servicio, y otras más pequeñas..."11

Aunque esta galería se convertiría en algo más que un simple sistema de comunicación peatonal. Corrales proponía un espacio intermedio de relación:

"... para establecer un espacio- que podría denominarse "intermedio"- entre el ámbito privado que es la vivienda y el espacio público. Hoy en día apenas hay espacios intermedios entre lo privado y lo público. Estos espacios han fracasado en nuestra geografia porque la gente no los quiere o porque no desea
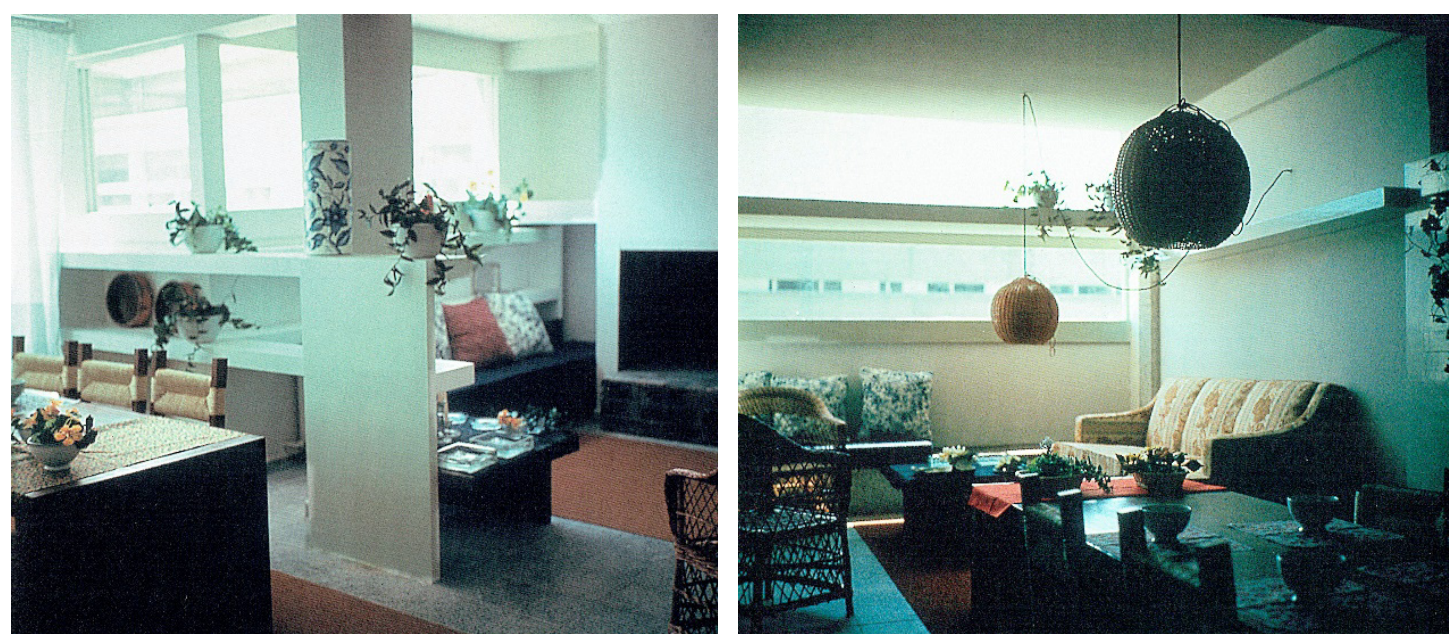

Fig. 8 (izquierda) y 9 (derecha): Interior vivienda-torre. Toba Blanco, M \& Bescansa I. 
relacionarse con el vecino. Algo así podría parecer que tiene interés desde un punto de vista sociológico, pero no es así. ${ }^{\prime 12}$

Proponía locales comerciales de uso inmediato $^{13}$ en la galería. Entre los locales, los núcleos de escaleras de acceso a las viviendas situadas sobre y bajo el nivel de la galería.

"Estos bloques tienen un afán comunitario y social, pues los vecinos se encuentran en los ascensores, en las galerías y en las tiendas." 14

"Creo que son ejemplo de la vivienda con un poco de expansión comunitaria, de manera que no se reduzca a un bloque aislado con un portal." 15

Proponía un comercio a tres niveles de proximidad. Los locales ubicados en la propia galería de circulación de $30 \mathrm{~m} 2$ y con $\mathrm{su}$ aseo correspondiente, y cuyo uso fuera compatible con la proximidad de las viviendas contemplando incluso poder ser usados como oficinas. Bajo el puente entre los bloques 1 y 2 , Corrales proyecta una pieza de tres plantas destinada a locales necesariamente más retirados por su uso y recorrida por una rampa de circulación abierta. Una tercera pieza para locales sobre el garaje, frente a la plaza, en dos plantas con soportal delantero y con acceso directo a la guardería anexa.

A la guardería se puede acceder desde la plaza posterior o desde la propia galería cubierta, permitiendo poder conducir a los niños a ella siempre bajo cubierto siguiendo la línea de galerías de bloques ${ }^{16}$.

Dado el alto número de viviendas requerido junto a la persecución de la máxima economía, Corrales buscaba viviendas de anchura mínima de fachada, $7 \mathrm{~m}$, y máxima profundidad llegando hasta $14,45 \mathrm{~m}$ - repitiendo en alzado un mismo tipo de hueco. El Lugar, en donde se ubicaba el proyecto, en un lenguaje actual, parecía hacerse presente como solución:

"Seguimos la idea de los cantones de La Coruña mediante un sistema de galerías de cristal. ${ }^{\prime 17}$

Ventanas correderas de $0,60 \times 1,00 \mathrm{~m}$ tipo Pearson recorren así las fachadas orientadas a norte hacia donde vuelcan todos los dormitorios. Flanqueando los huecos y formando parte de la fachada, armario alto en la parte alta y banco corrido bajo el vano se repiten de manera sistemática hacia el interior. En las fachadas orientadas al sur, Corrales repite el sistema, sustituyendo en los salones-estar, el armario alto por luna fija buscando introducir mayor cantidad de luz a estas estancias más profundas. Los distintos retranqueos de los bloques y su perfil variable, evitan en todo momento la sensación de monotonía y repetición.

El sistema de huecos también sería empleado en las viviendas individuales y en las torres, abriendo en éstas también en los testeros miradores acristalados.

Corrales: "El hueco de la ventana continua adoptada nos obligó a incluir un cargadero continuo bajo el cerramiento que une a ambos elementos, es decir, que se trata de un elemento que cumple ambas funciones. Nacía de este modo 'el colgante de hormigón'."18

Este hueco continuo escondía al interior de los bloques siete tipos diferentes de viviendas -dos de ellos en dúplex- de entre tres y cinco dormitorios. Las torres y las viviendas unifamiliares, disponían de su propia planta diferenciada. Con una distribución clara y efectiva orientada al sol, Corrales disponía los dormitorios orientados siempre a norte, sin excepción, y el estar-comedor a mediodía. Se completaba éste, según los casos, con dormitorio auxiliar que se podría incorporar al estar. Baños y oficio, discurrían por el interior de la planta junto a la cocina que conseguía iluminación y ventilación natural mediante patio de servicio hacia la fachada sur.

El estar-comedor presentaba distinta cota, de $30 \mathrm{~cm}$, independizando ambientes y permitiendo una mayor entrada de luz diagonal por el ventanal abierto en fachada. La mayoría de las viviendas disponía de chimenea en esta estancia.

Corrales, también contemplaba la solución pormenorizada para los interiores, llegando a definir incluso parte del mobiliario fijo. Elementos de obra en el mismo color que las paredes y naciendo de la fachada ayudan a organizar el espacio completado por cada inquilino con sus propios muebles. Baldas, estantes, repisas y aparadores enlazados con los pilares vistos o incluso la chimenea participan de esa misión, con la misma estética escultural de los exteriores.

Andrés Fernández Albalat: "Lo de introducir el mobiliario fue una cosa que José Antonio 

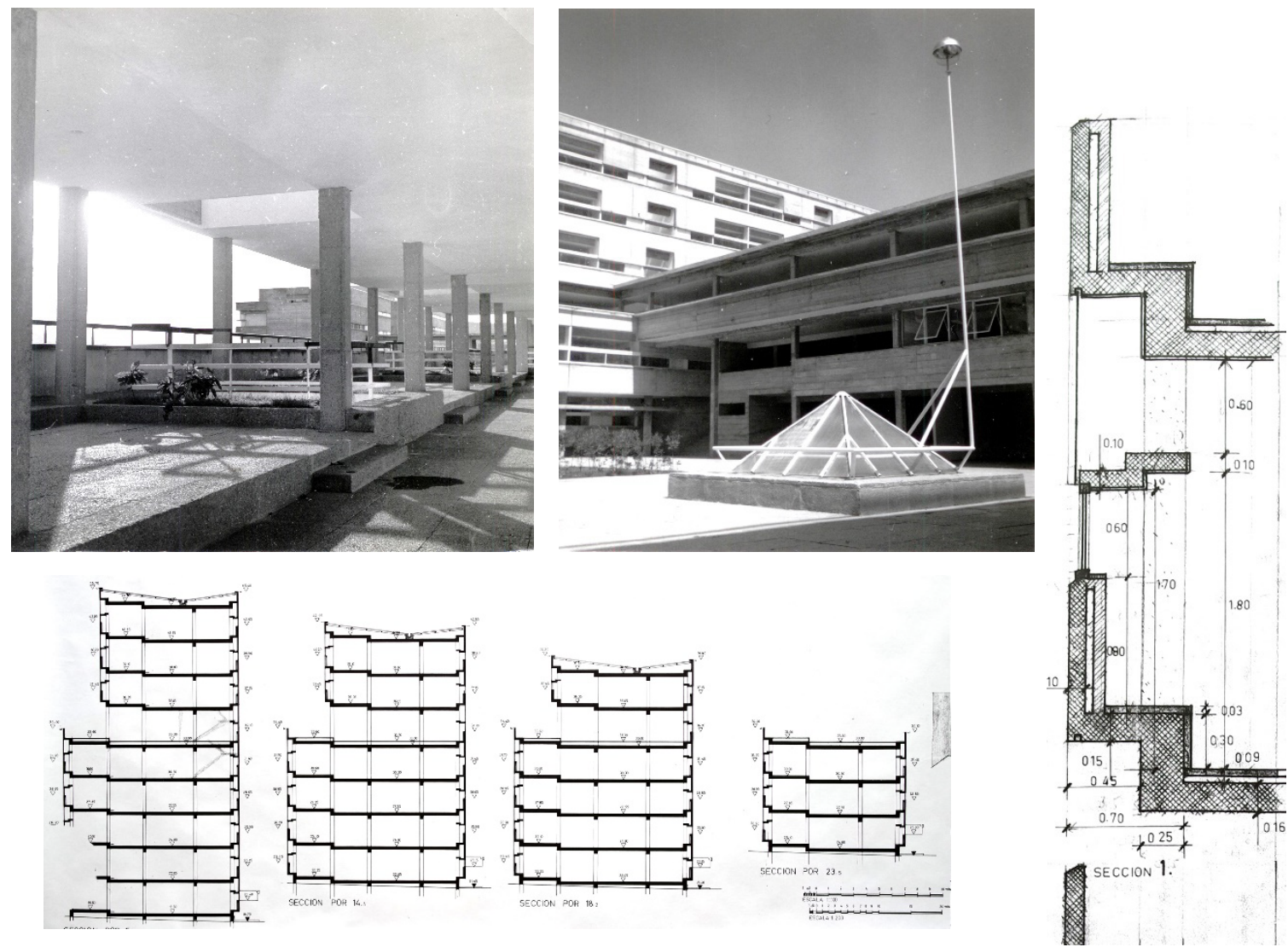

Fig. 10: Izquierda, arriba. Interior galería. Archivo Corrales.

Fig. 11: Centro, arriba. Plaza sobre garaje y galería comercial. Archivo Corrales.

Fig. 12: Izquierda, abajo. Secciones bloque 3. Archivo Corrales.

Fig. 13: Derecha. Sección-tipo viviendas. Alzados mediodía. Archivo Corrales.

hizo con la colaboración de su mujer, Peque Corrales, muy introducida en ese ámbito. Lo que hicieron entonces fue amueblar una de las torres para la inauguración, para que se pudiese visualizar cómo era posible decorar las viviendas con poco dinero." 19

José Antonio Corrales nos propone para Elviña una Ciudad Compacta desde el planteamiento general al detalle, donde las partes y el todo se confundan. Con un manejo elaborado de las secciones respondiendo a cada cuestión y escala, organizadas por las plantas en su trazado esencial. Una Ciudad Compacta, fruto de la mirada utópica y sincera de su autor persiguiendo una manera de vivir optimista, abierta y comunicativa. En donde los nexos y límites han desaparecido y sus habitantes pudieran vivir felices mirando al sol.

\section{Notas}

1 Corrales, J.A. Proyecto 074. Plan General de Ordenación de La Coruña. Proyecto de revisión del Plan de 1948. Ayuntamiento de La Coruña. Arquitectos: J.A. Corrales. R.V. Molezún, J.M. Pagola. Fecha: enero 1965. Archivo J.A. Corrales. Madrid.

2 Benévolo, L. 2002. Historia de la Arquitectura Moderna. Barcelona: Gustavo Gili. p. 965.

3 Ibíd. p. 920.

4 Corrales, J.A. Proyecto 067. Grupo de viviendas en el Polígono de Elviña. La Coruña. Barrio de las Flores. Prop. Obra Sindical del Hogar y Arquitectura. Fecha: febrero 1964/65. Memoria del proyecto. Archivo J.A. Corrales. Madrid. p.1

5 Corrales, J.A. 1968. "Unidad vecinal núm. 
3. Barrio de Las Flores. Polígono de ElviñaLa Coruña". Arquitectura. Madrid: Colegio Oficial de Arquitectos de Madrid. no 117. p 5

6 Toba Blanco, M., \& Bescansa, I. 2009. José Antonio Corrales: Unidad vecinal $\mathrm{n}^{\circ} 3$. Coruña. COAG p. 63

7 Ibíd. p. 64

8 Corrales, J.A. 1968. "Unidad vecinal núm. 3. Barrio de Las Flores. Polígono de ElviñaLa Coruña". Arquitectura. Madrid: Colegio Oficial de Arquitectos de Madrid. no 117. p 6

9 Toba Blanco, M., \& Bescansa, I. 2009. José Antonio Corrales: Unidad vecinal $\mathrm{n}^{\circ} 3$. Coruña. COAG p. 92

10 Corrales, J.A. Proyecto 067. Grupo de viviendas en el Polígono de Elviña. La Coruña. Barrio de las Flores. Prop. Obra Sindical del Hogar y Arquitectura. Fecha: febrero 1964/65. Memoria del proyecto. Archivo J.A. Corrales. Madrid. p.10-11

11 Toba Blanco, M., \& Bescansa, I. 2009. José Antonio Corrales: Unidad vecinal $\mathrm{n}^{\circ} 3$. Coruña. COAG p. 64

12 Ibíd. p. 83

13 José Antonio Corrales. Barrio y Ciudad. [videograbación] Colegio Oficial de Arquitectos de Galicia. 6/4/2006. 1 DVD, (100 min.): son., col. Material complementario en Toba Blanco, M., \& Bescansa, I. 2009. José Antonio Corrales: Unidad vecinal $n^{\circ} 3$. Coruña. COAG.

14 Corrales, José Antonio. 2000. José Antonio Corrales, obra construida. Pamplona, T6 Ediciones p. 25

15 Ibíd. p. 25

16 Corrales, J.A. Proyecto 067. Grupo de viviendas en el Polígono de Elviña. La Coruña. Barrio de las Flores. Prop. Obra Sindical del Hogar y Arquitectura. Fecha: febrero 1964/65. Memoria del proyecto. Archivo J.A. Corrales. Madrid. p.9

17 Corrales, José Antonio. 2000. José Antonio Corrales, obra construida. Pamplona, T6 Ediciones p.24

18 Toba Blanco, M., \& Bescansa, I. 2009. José Antonio Corrales: Unidad vecinal $\mathrm{n}^{\circ} 3$. Coruña. COAG p. 69

19 Ibíd. p. 119

\section{Referencias}

Archivos de José Antonio Corrales y Ramón Vázquez Molezún.

Benévolo, Leonardo. 2002. Historia de la Arquitectura Moderna. Barcelona: Gustavo Gili.

Corrales, José Antonio. 1983. J.A. Corrales, R.V. Molezún, Arquitectura. Madrid: Xarait Ediciones, ISBN 84-85434-17-X

Corrales, José Antonio. 2000. José Antonio Corrales, obra construida. Pamplona: T6 Ediciones, ISBN 84/89713-33-2

Corrales, José Antonio. 2005. Cultura del proyecto (III). Conversaciones con Javier Seguí de la Riva. Madrid: Cuadernos del Instituto Juan de Herrera, Escuela de Arquitectura de Madrid, ISBN978-84-9728179-9

Corrales, José Antonio. 2007. José Antonio Corrales, Premio Nacional de Arquitectura 2001, Madrid: Ministerio de la Vivienda, Secretaría General Técnica, ISBN 978-8496387-07-2

Corrales Gutiérrez, J., Cánovas Alcocer, A., \& España Ministerio de la Vivienda. 2005. Pabellón de Bruselas '58: Corrales y Molezún. Madrid: Ministerio de la Vivienda, ETS Arquitectura, Departamento de Proyectos. Madrid. ISBN 84-933262-4-0

Frampton, K. 2009. Historia crítica de la arquitectura moderna. Barcelona: Gustavo Gili.

Fullaondo, J.D., Muñoz, M.T. y otros. 1993. Corrales y Molezún: Medalla de Oro de la Arquitectura 1992. Madrid: Consejo Superior de los Colegios de Arquitectos de España.

Toba Blanco, M., \& Bescansa, I. 2009. José Antonio Corrales: Unidad vecinal $\mathrm{n}^{\mathrm{0}} 3$. Coruña: COAG. ISBN 978-84-96712-09-6

Olalquiaga Bescós, P. 2014. Casa Huarte: José Antonio Corrales y Ramón Vázquez Molezún. El concepto de lo experimental en el ámbito doméstico. Tesis Doctoral. Universidad Politécnica de Madrid. E.T.S. Arquitectura. 